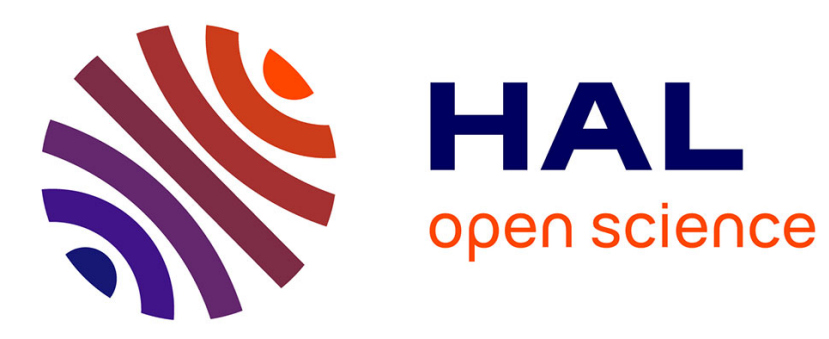

\title{
Deformation modes of nanostructured thin film under controlled biaxial deformation
}

Soundes Djaziri, Damien Faurie, Eric Le Bourhis, Philippe Goudeau, Pierre-Olivier Renault, Christian Mocuta, Dominique Thiaudière, François Hild

\section{To cite this version:}

Soundes Djaziri, Damien Faurie, Eric Le Bourhis, Philippe Goudeau, Pierre-Olivier Renault, et al.. Deformation modes of nanostructured thin film under controlled biaxial deformation. Thin Solid Films, 2013, 530, pp.30-34. 10.1016/j.tsf.2012.05.051 . hal-00947392

\section{HAL Id: hal-00947392 https://hal.science/hal-00947392}

Submitted on 20 Feb 2014

HAL is a multi-disciplinary open access archive for the deposit and dissemination of scientific research documents, whether they are published or not. The documents may come from teaching and research institutions in France or abroad, or from public or private research centers.
L'archive ouverte pluridisciplinaire HAL, est destinée au dépôt et à la diffusion de documents scientifiques de niveau recherche, publiés ou non, émanant des établissements d'enseignement et de recherche français ou étrangers, des laboratoires publics ou privés. 


\title{
Deformation modes of nanostructured thin film under controlled biaxial deformation
}

S. Djaziri ${ }^{1}$, D. Faurie ${ }^{2}$, E. Le Bourhis ${ }^{1}$, Ph. Goudeau ${ }^{1}$, P.-O. Renault ${ }^{1}$, C. Mocuta ${ }^{3}$, D. Thiaudière $^{3}$, F. Hild ${ }^{4}$

${ }^{1}$ Institut PPRIME - CNRS/Université de Poitiers/ENSMA, Bd Marie et Pierre Curie, BP 30179 - 86962 Futuroscope, France

${ }^{2}$ LSPM - CNRS Université Paris 13, 99 Avenue J.B. Clément, 93430 Villetaneuse, France

${ }^{3}$ Synchrotron SOLEIL, L'Orme des Merisiers, BP 48, 91192 Gif sur Yvette, France

${ }^{4}$ LMT Cachan - ENS Cachan/CNRS/UPMC/PRES UniverSud Paris, 61 Av. du Président Wilson 94235 Cachan, France

\begin{abstract}
This paper reports on the mechanical behaviour of nanostructured $\mathrm{W} / \mathrm{Cu}$ thin films deposited on Kapton ${ }^{\circledR}$ under controlled biaxial loadings thanks to a biaxial testing device developed on DiffAbs beamline at SOLEIL synchrotron (Saint-Aubin, France). In situ tensile tests were carried out combining 2D synchrotron x-ray diffraction (XRD) and digital-image correlation (DIC) techniques. First, the elastic behaviour of the composite metallic film - polymeric substrate was investigated under equi-biaxial and non-equibiaxial loading conditions. The results show that the strain measurements (in the crystalline film by XRD and the substrate by DIC) match to within $10^{-4}$. This result demonstrates the full transmission of strains in the elastic domain through the film-substrate interface and thus a good adhesion of the thin film to the substrate. The second part of the paper deals with higher strains response under equi-biaxial tensile tests. The elastic limit of the nanostructured $\mathrm{W} / \mathrm{Cu}$ thin films was determined at the bifurcation point between strains obtained by XRD and DIC. Deformation mechanisms such as strain localisation and film fragmentation are proposed.
\end{abstract}

\section{Keywords}

synchrotron x-ray diffraction, digital image correlation, biaxial deformation, elastic limit, nanostructured $\mathrm{W} / \mathrm{Cu}$ thin films 


\section{Introduction}

Nanostructured refractory metals, such as nanostructured tungsten (W), offer a great potential for applications in critical conditions such as aerospace, electronics, lighting and medicine [1-4] due to their high melting point, good mechanical and physical properties [57]. Ion beam sputtering techniques employing a multilayer elaboration process is used in this work to fabricate nanostructured $\mathrm{W}$ thin films. The method consists in sputtering tungsten and copper (two immiscible metals) alternatively on polyimide substrates with the control of the thickness of each sub-layer in the nanometre range [8]. The obtained composites present interesting properties including good conductivity (thermal and electrical), enhanced mechanical properties (high strength of $\mathrm{W}$ combined with improved ductility of $\mathrm{Cu}$ ) [1, 9-10] and a flexible polymer substrate for use in technological applications such as sensors and stretchable microelectronics components [11-13]. Given the complex microstructure of the nanostructured materials due to the small grain size, strong crystallographic texture, high density of defects and significant grain boundary areas [14-17], their mechanical behaviour is particularly affected and not well understood yet.

Several studies reported that mechanical behaviour of layered composites becomes affected when the layer thickness lies in the nanometre range. Size effects are observed for sub-micron structures. The grain size is found to decrease with decreasing film thickness, which induces a strong increase of both the yield stress and strain hardening rate [18-22]. In particular, high hardness is observed in nanolayered composites that result from a combination of increased yield strength and increased work hardening rate at low layer thicknesses [23-26]. This results from the change of deformation mechanisms and sizedependent mechanisms of plasticity for materials at the nanoscale [27-30].

Different mechanical methods have been used to investigate the strength of metal thin films such as tensile testing, indentation and bending technique [31-37]. However, these tests still do not necessarily reflect the real conditions of systems in use. Biaxial tests allow 
mimicking real operating conditions. Although some biaxial tests have been developed, the most available experiments are restricted to equi-biaxial loadings and often with crucial sample preparation such as bulge testing [38] and ring-on-ring tests [39].

In this work, the elastic-plastic behaviour of nanostructured $\mathrm{W}$ thin films deposited on Kapton $^{\circledR}$ was investigated under different controlled biaxial loadings thanks to a testing device developed on DiffAbs beamline at SOLEIL synchrotron (Saint-Aubin, France) [40]. In particular, equi-biaxial and non-equi-biaxial loading conditions have been applied. The in-grain strain of thin films was investigated by synchrotron x-ray diffraction (XRD) technique with a hybrid-pixel area detector XPAD3.1 used for its low noise and high dynamic range [41] while the macroscopic strain of the Kapton ${ }^{\circledR}$ substrate was monitored thanks to digital image correlation (DIC). We illustrate the use of these combined techniques in order to obtain the elastic limit of nanostructured $\mathrm{W} / \mathrm{Cu}$ thin films.

\section{Experiments}

\subsection{Samples}

Nanostructured $\mathrm{W}$ thin films were fabricated by introducing $\mathrm{Cu}$ as an immiscible interlayer into $\mathrm{W}$ thin films [11]. The process is based on sputtering alternatively $\mathrm{W}$ and $\mathrm{Cu}$ on $127-$ $\mu \mathrm{m}$-thick polyimide $\left(\operatorname{Kapton}^{\circledR}\right)$ cruciform substrate. The thin films were produced at room temperature by physical vapour deposition in a central area of $20 \mathrm{~mm}$ in diameter of the cruciform polyimide substrate, which has 20 -mm wide arms and a 5 -mm toe weld.

Two thin films were fabricated with two different number of W-Cu bi-layers (called periods), namely, 60 periods $(217 \pm 10 \mathrm{~nm}$ total thickness $)$ and 38 periods $(140 \pm 10 \mathrm{~nm}$ total thickness). The deposition time of each $\mathrm{W}$ and $\mathrm{Cu}$ layers was $60 \mathrm{~s}$ and $7 \mathrm{~s}$, respectively, with an average growing rate for $\mathrm{W}$ and $\mathrm{Cu}$ of $0.05 \mathrm{~nm} / \mathrm{s}$ and $0.07 \mathrm{~nm} / \mathrm{s}$, respectively. The nominal thicknesses both $\mathrm{W}$ and $\mathrm{Cu}$ sub-layers were 3 and $1 \mathrm{~nm}$, respectively. Details about the deposition method and thickness measurements are 
described in Ref. [42]. The effective period thickness was about $3.7 \mathrm{~nm}$ in which $\mathrm{Cu}$ represents $13 \%$ of the total thickness. The obtained microstructure consists of equiaxed grains with an average size close to the sub-layer thickness [8] and the crystallographic texture of $\mathrm{W}$ sub-layers is predominantly a $\{110\}$-fibre texture with a dispersion of approximately $18^{\circ}$ for the two thin films [40]. The thin films are subjected to high compressive residual stresses $\left(\sigma_{W}^{\mathrm{Re} s}=-3.3 \pm 0.4 \mathrm{GPa}\right.$ ) obtained by x-ray diffraction stress analysis in W phase [43-44]. The origin of the compressive stress in tungsten thin films is due basically to deposition processing: ion beam sputtering induces high compressive stress state by atomic peening process [45-47]. Noticeably, the x-ray stress analysis in W phase is much simpler than general cases because $\mathrm{W}$ is a perfect isotropic material from the mechanical point of view $[36,48]$.

\subsection{Strain measurements}

The samples have been loaded biaxially thanks to the biaxial testing device developed on the DiffAbs beamline at SOLEIL synchrotron. This machine was designed to allow for loadings along two perpendicular axes of cruciform substrates coated at their centre by the studied films (no adhesion layer was deposited). Further information about this biaxial device can be found in Ref. [40]. The polyimide substrate (Kapton ${ }^{\circledR} \mathrm{HN}$ from DuPont ${ }^{\mathrm{TM}}$ ) is expected to behave elastically in a strain range of about $4-5 \%$.

Strain measurements have been performed for equi-biaxial and non equi-biaxial loadings using both $\mathrm{x}$-ray diffraction and digital image correlation techniques. Therefore, the mechanical behaviour of the sample was obtained at two different scales. At the microscale, XRD was used to measure strains within the $\mathrm{W}$ metal coating over coherent diffraction domains. At the macro-scale, DIC was used to assess macroscopic applied strains in the polyimide cruciform substrate. The image of the bottom side of the substrate (the uncoated side) was captured using a CCD camera [42]. The applied loads are incrementally increased from the initial loading state. For $[\mathrm{W}-\mathrm{Cu}] \times 60$ periods, the load 
range was between 0 and $40 \mathrm{~N}$ for excursions in the elastic domain, while the applied loads ranged from 0 to $160 \mathrm{~N}$ for $[\mathrm{W}-\mathrm{Cu}] \times 38$ periods (excursions above the elastic limit). Tensile tests were performed in quasi-static conditions; for each applied load, DIC measurements were performed by recording a set of ten images of the non-coated surface of the polyimide substrate before and after XRD measurements conducted on $\mathrm{W} / \mathrm{Cu}$ thin films.

\subsubsection{Synchrotron X-ray diffraction: in-grain strains}

Highly accurate and reliable strain measurements can be achieved by exploiting x-ray synchrotron radiation. X-ray synchrotron radiation has unique properties compared to standard x-ray sources, namely, high flux, high brilliance, a wide range of photon energy tunability and a well-defined polarization state of the emitted radiation. The first characteristic is particularly interesting for the study of nanostructured thin films due to the very small diffracting volumes and the nano-size of its grains. Performing x-ray diffraction measurements with a hybrid pixel detector XPAD3.1, strain measurements are achieved in short counting times with good accuracy. Thus, sample creep and substrate relaxation can be avoided. For our experiments, the $2 \mathrm{D}$ detector is mainly interesting for its fast read-out time (2 ms), a large dynamic range (27 bits) and a very low noise [41].

In this study, the x-ray energy and beam size have been set to $8.8 \mathrm{keV}$ and $0.320 \times 0.370 \mathrm{~mm}^{2}$ (full width at half maximum, horizontal $\times$ vertical), respectively. Diffraction patterns were recorded with the XPAD3.1 detector placed on the 2-theta in the vertical plane of the 6-circle Kappa goniometer of DiffAbs beamline at $536 \mathrm{~mm}$ away from the sample. The measurements have been performed for the $\{211\}$ lattice planes of the $\alpha$ W-phase using $\sin ^{2} \Psi$ method since measurements at high angle diffraction peaks are more accurate than those at low angle peaks with a good compromise in the diffraction intensity for the $\{211\}$ lattice planes $[43,48]$. In particular, twenty six different tilt-angles $\Psi$ have been used for two azimuth directions $\left(\Phi=0^{\circ}\right.$ and $\Phi=90^{\circ}$; corresponding to the two 
loading directions of the cruciform sample). This number of experimental points allows for accurate and reliable strain measurements as illustrated in Section 3. Applied in-grain strains were determined from the diffraction peak shifts according to Bragg's law for each applied load step. Peaks diagram was obtained by an azimuthally integration along the radial direction of 2D diffraction patterns collected from the 2D detector.

In the case of an equi-biaxial planar stress state, as usually used [49], the in-grain strain $\{\varepsilon\}_{\Phi \Psi}^{\mathrm{hkl}}$ corresponding to $\{\mathrm{hkl}\}$ diffracting planes and a scattering vector with orientation $(\Phi, \psi)$ is given by

$$
\left\{\varepsilon_{\Phi \Psi}^{\mathrm{hkl}}=\ln \left(\frac{\mathrm{d}_{\Phi \Psi}}{\mathrm{d}_{\Phi \Psi}^{(0)}}\right)=\ln \left(\frac{\sin \theta_{\Phi \Psi}^{(0)}}{\sin \theta_{\Phi \Psi}}\right)=\left[\left(\varepsilon_{\mathrm{xx}}^{\mathrm{Appl}}+\varepsilon_{\mathrm{xx}}^{\mathrm{Res}}\right)-\left(\varepsilon_{\mathrm{zz}}^{\mathrm{Appl}}+\varepsilon_{\mathrm{zz}}^{\mathrm{Res}}\right)\right] \sin ^{2} \Psi+\left[\varepsilon_{\mathrm{zz}}^{\mathrm{Appl}}+\varepsilon_{\mathrm{zz}}^{\mathrm{Res}}\right]\right.
$$

where $d_{\Phi \Psi}^{(0)}$ is the reference lattice spacing, and $\theta_{\Phi \Psi}^{(0)}$ the associated reference diffraction angle, it corresponds here to the unloaded state. $d_{\Phi \Psi}$ and $\theta_{\Phi \Psi}$ are the lattice spacing and the diffraction angle, respectively, for the loaded states. $\varepsilon_{\mathrm{xx}}$ and $\varepsilon_{\mathrm{zz}}$ correspond to in-plane and out-of-plane strains respectively. The superscript Appl (respectively Res) is related to the applied (respectively residual) strains. The XRD total strains (residual + applied) can be calculated from $\ln (1 / \sin \theta)$ versus $\sin ^{2}$ psi plots. In order to obtain the XRD applied strain, the first load state is considered as the reference state [50].

\subsubsection{Digital image correlation: macroscopic strain}

Digital image correlation was used to investigate the mechanical response of the polyimide substrate. This technique is interesting and well adapted to assess large strains of polymers with high accuracy since x-ray diffraction method is restricted to measure elastic strains in crystalline materials. The DIC technique measures the displacement field $\overline{\mathbf{u}}$ of one image of the deformed configuration with respect to the reference image of the sample surface; $\overline{\mathbf{u}}$ is determined by correlating the grey scale distribution between the two images. In order to obtain different grey levels, the rear surface of the polyimide substrate (non-coated face) 
was spray-painted with a speckle pattern. Digital images of the sample surface were recorded by a CCD camera where the size of the captured region is $9 \times 6.3 \mathrm{~mm}^{2}$. The $\mathrm{CCD}$ camera (pixelfly qe) is very interesting for its high resolution $(1392 \times 1024$ pixel, $\mathrm{H} \times \mathrm{V})$, 12 bit dynamic range and a pixel size of $6.45 \times 6.45 \mu \mathrm{m}^{2}$.

The displacement field $\overline{\mathbf{u}}$ relates the reference and deformed states (called $f(\mathbf{x})$ and $g(\mathbf{x})$ respectively at a point of coordinate $\mathrm{x}$ ) by requiring the conservation of grey levels [51]

$$
\mathrm{f}(\mathbf{x})=\mathrm{g}[\mathbf{x}+\overline{\mathbf{u}}(\mathbf{x})]
$$

For each applied load, a set of ten images (one image per second) was recorded in order to improve statistics and accuracy of the measurements. Applied macroscopic strains have been checked to be uniform in a central area of $8 \mathrm{~mm}$ in diameter of the cruciform polyimide substrate. More details about these measurements are given in Ref. [42].

\section{Results and discussion}

\subsection{XPAD- image processing}

The procedure consisted in geometrical corrections and intensity integration of each image using an algorithm that was programmed in ImageJ macro language. The diffraction images were recorded with the XPAD3.1 detector [41]. The measurements have been restricted to selected parts of the diffraction pattern (Fig. 1a) due to the large sample to detector distance that was necessary in order to avoid collision during the measurements.

The geometrical correction for the tilting and the overlap of the modules due to the tiling design of the XPAD3.1 detector has been applied by taking into account the module shifts measured with a metallic grid. Moreover, double pixels are present on the edges of each chip composing the detector modules. These pixels are replaced by 2.5 pixels of the same size as the others and by renormalizing the measured intensities by a factor $1 / 2.5$. The nonuniform response of the detector that induces image distortions was corrected by dividing each image by the flat field signal. Thus, a new corrected image is generated (Fig. 1b). 
Then, each diffraction image was converted by a radial integration method to a onedimensional $2 \theta$ scan as seen in Fig. 1c. Figure 1c shows a peak with a good signal to noise ratio but with missing data points resulting from the shadows existing between XPAD modules. Details concerning the correction method are described in Ref. [52].

\subsection{Strain measurements}

First, the elastic behaviour of the nanostructured $\mathrm{W}$ thin film was investigated under equibiaxial and non-equi-biaxial loading conditions combining synchrotron XRD and DIC techniques. Next, the mechanical study was extended to the plastic behaviour.

\subsubsection{Elastic response}

The composite $[\mathrm{W}-\mathrm{Cu}] \times 60$ periods was subjected to equi-biaxial and non-equi-biaxial loadings restricted to the elastic domain. The two strain components have been extracted from XRD measurements as well as DIC measurements. Figure 2 shows the obtained results for both loading paths and we can see a good agreement between XRD and DIC strains. The results show the two strain measurements match to within $10^{-4}$ in the elastic domain for strain levels less than $0.3 \%$, and for both loading paths. It is worth noting that the non equi-biaxial path goes through equi-biaxial loadings. These results illustrate the opportunity of employing both DIC and XRD with a high dynamic range. It is noteworthy to recall each XRD point of the curve is the result of the analysis of seventeen $\Psi$ experimental points obtained thanks to the XPAD detector. Validation has been achieved by checking the measurement accuracy and the method reliability for the two types of analyses (synchrotron XRD and DIC) for which thin films deposited on polymer substrate have been adopted [42]. The consequence of the accuracy of the two strain measurements techniques is that the applied strain is determined to be transmitted unchanged in the elastic domain through the metallic film - polymeric substrate interface although no adhesion layer was used as already reported for gold films [53]. 


\subsubsection{Response above the elastic limit}

Equi-biaxial tensile tests have been carried out for the composite $[\mathrm{W}-\mathrm{Cu}] \times 38$ periods at higher applied strains, i.e. the mechanical test is extended into the plastic regime of the metallic thin film. Figure 3 shows the complete set of $\ln (1 / \sin \theta)-\sin ^{2} \Psi$ plots. This figure reflects the change of the total stress (residual and applied) within $\mathrm{W}$ grains during the tensile test. The total stress is first compressive and decreases when the applied load is increased. Then, it is reversed to tensile going through a zero total stress at an applied load of $88.7 \mathrm{~N}$ approximately. As clearly shown (inset of fig. 3), the slope of $\ln (1 / \sin \theta)-\sin ^{2} \Psi$ linear regressions is going from negative to positive values. The total stress becomes almost constant when an applied load of $\sim 100 \mathrm{~N}$ is reached. XRD measurements have been performed for twenty six tilt-angles $\Psi$ as can be seen in Fig. 4 . The obtained applied x-ray strains as functions of the applied load demonstrate Poisson's effect on the different oriented W grains. $\{211\}$ planes family parallel to the film surface is subjected to compressive applied strains. However, $\{211\}$ planes family perpendicular to the film surface is subjected to tensile applied strains. Hence, the measured x-ray strain is either negative or positive depending on the measurement direction. It is worth noting that some planes family with a particular orientation are not subjected to any applied strain as can be observed for the x-ray strain obtained at tilt $\Psi$ around $45^{\circ}$. We observe a single crossing point over all the loading state indicating the conservation of the stress-free parameter.

As shown in the previous section, DIC measurements have been confronted to those obtained by XRD in this study also. Figures 5 and 6 present the obtained applied strains measured by the two techniques. Applied x-ray strain in the film increases, as the applied macroscopic strain in the polyimide substrate, up to an applied load of $\sim 75 \mathrm{~N}$ (domain I, 
Fig. 5). Above this load, the film response departs from the substrate one (beginning of domain II). In this domain, the substrate deforms non-linearly (viscoelastic behaviour). In contrast, the film applied strain still increases linearly up to an applied load of $\sim 100 \mathrm{~N}$ (i.e. a corresponding strain of $0.67 \%$ ). This observation emphasizes the need of measuring both substrate and film strains with high accuracy to determine the elastic limit. Domain III starts when the elastic strain saturates.

Figure 6 shows the XRD elastic strains versus DIC strains and introduces the adopted method to determine the elastic limit of the thin film. It has been shown (Section 3.2.1) that the applied strain in the elastic domain is fully transmitted through the film - substrate interface. Then, the elastic limit is determined when the x-ray strain is no longer equal to the macroscopic strain. This XRD strain-DIC strain relationship could be reasonably well fitted by a two-degree polynomial: $\varepsilon=-4.8 \times 10^{-1} \bar{\varepsilon}^{2}+1.3 \bar{\varepsilon}-3.1 \times 10^{-2}$

where $\varepsilon$ (respectively $\bar{\varepsilon}$ ) is the strain measured by XRD (respectively DIC) technique. To perform the fitting procedure, the data have been chosen in a range from 0 to $0.7 \%$. Here, the elastic limit defined as the domain I limit (Figure 6) is determined at the point where the linear plot and the fitted equation differ by more than $0.02 \%$. Following the above criterion, the elastic limit is around $0.5 \%$. It corresponds to an equi-biaxial applied stress of $2.9 \mathrm{GPa}$ in the crystalline part of the $\mathrm{W}$ phase. Taking into account of the as-deposited residual stress state, i.e. $\sigma_{W}^{\mathrm{Re} s}=-3.3 \pm 0.4 G P a$, the apparent elastic limit corresponds to a total compressive stress of $\sim-0.4 \pm 0.4 G P a$ in $\mathrm{W}$ crystalline phase.

The redistribution of applied strain may be induced either by slip, decohesion at the interface, or by strain partitioning in the different phases (grain boundaries, $\mathrm{W}$ and $\mathrm{Cu}$ crystalline phases) or by microcracks generation. Dislocation mobility and multiplication should be hindered for $\mathrm{W}$ nanometric grains $[21,54]$. Noticeably, we expect a very high 
volume fraction of grain boundaries. Hence, we propose that within domain II (Figure 6) deformation localises at grain boundaries and/or copper grains and extends progressively with the observed strain increase. Within domain III, as suggested by Frank et al. in the case of brittle Ta layers on polyimide substrates uniaxially tested [55], the observed x-ray strain saturation measured in the crystalline $\mathrm{W}$ part could be attributed to the onset and development of film fragmentation. Additional observations are under progress to localize the fragmentation and determine the influence of the biaxial loading on the cracks distribution and morphology.

In summary, the deformation of the tungsten thin film is purely elastic within domain I since the XRD applied strain (i.e. elastic applied strain) is equal to the DIC applied strain (macroscopic applied strain). Within domain II, the $\mathrm{W}$ thin film strain starts to depart from the substrate one but the film continues to deform partly elastically as revealed by the increase of XRD strain. This observation may be attributed to decohesion at the interface or by microcracks generation. Within domain III, we observe a saturation of the applied elastic strain while the macroscopic strain increases significantly; this is attributed to the onset of film fragmentation.

\section{Conclusions}

In this paper, we have presented a combined method for studying metal thin films deposited on Kapton ${ }^{\circledR}$. Accurate in-grain strains could be measured employing synchrotron $\mathrm{x}$-ray diffraction with a low noise and a high dynamic range pixelated area detector (XPAD). The substrate global strain was determined by digital image correlation. The two strain (obtained at two different length scales) match to within $10^{-4}$. Comparison of strain measurements of nanostructured $\mathrm{W}$ thin films studied in the elastic domain under two different biaxial loading conditions (equi and non equi-biaxial) demonstrates the good quality and the reliability of the measurements. The elastic limit of the nanostructured 
$\mathrm{W} / \mathrm{Cu}$ thin films was determined at the bifurcation point $(\sim 0.5 \%)$ between strains obtained by XRD and DIC when the in-grain elastic total stress is compressive $(-0.4 \pm 0.4 G P a)$. The excursion above the elastic limit has been achieved thanks to a high number of measurement points with a good accuracy. The deviation between substrate and film strains is attributed to strain localisation followed by the onset of fragmentation. Further experiments are planned to scrutinize the crack development in such nanocrystalline structures.

\section{Acknowledgments}

We like to thank Yannick Diot and Philippe Guérin from the PPRIME institute for samples preparation. 


\section{References}

[1] P. M. Geffroy, T. Chartier, and J. F. Silvain, Adv. Eng. Mater. 9 (2007) 547 .

[2] B. L. Mordike, J. Kaczmar, M. Kielbinski, and K. U. Kainer, Powder Metall. Int. 23 (1991) 91.

[3] A. Neubrand and J. Rödel, Z. Metallkd. 88 (1997) 358.

[4] Y. D. Kim, N. L. Oh, S. T. Oh, and I. H. Moon, Mater. Lett. 51 (2001) 420.

[5] F. A. Cotton, G. Wilkinson, C.A. Murillo, and M. Bochmann, in Advanced Inorganic Chemistry, John Wiley \& Sons, 1999.

[6] C. Wang, P. Brault, T. Sauvage, Eur. Phys. J. Appl. Phys., 31 (2005) 17.

[7] V.P. Godbole, G. Deokar, Scr. Mater. 62 (2010) 337.

[8] B. Girault, D. Eyidi, T. Chauveau, D. Babonneau, P.-O. Renault, E. Le Bourhis, P. Goudeau, J. Appl. Phys. 109 (2011) 014305.

[9] S. Saito, K. Fukaya, S. Ishiyama, K. Sato, J. Nucl. Mater. 307-311 (2002) 1542.

[10] A. Luedtke, Adv. Eng. Mater. 6 (2004) 142

[11] W.T. Li, R.B. Charters, B. Luther-Davies, L. Mar, Appl. Surf. Sci. 233 (2004) 227.

[12] S.P. Lacour, D. Chan, S. Wagner, T. Li, Z. Suo, Appl. Phys. Lett. 88 (2006) 204103.

[13] M.A. Meyers, A. Mishra, D.J. Benson, Prog. Mater. Sci. 51 (2006) 427.

[14] D. Faurie, P.-O. Renault, E. Le Bourhis, Ph. Goudeau, Acta Mater., 54 (2006) 4503.

[15] K.J. Martinschitz, R. Daniel, C. Mitterer, J. Keckes, J. Appl. Cryst. 42 (2009) 416.

[16] P.A. Gruber, E. Arzt, R. Spolenak, J. Mater. Res., 24 (2009) 1906.

[17] A.M. Vodnick, D.E. Nowak, S. Labat, O. Thomas, S.P. Baker, Acta. Mater. 58 (2010) 2452.

[18] C.A. Volkert, E.T. Lilleodden, Philosophical Magazine, 86 (2006) 5567.

[19] D.Wang, C.A. Volkert, O. Kraft, Mater. Sci. Eng. A 493 (2008) 267.

[20] J. Wang, R.G. Hoagland, X.Y. Liu, A. Misra, Acta Mater. 59 (2011) 3164.

[21] Gruber P. A., Böhm J., Onuseit F., Wanner A., Spolenak R., Arzt E., Acta Materialia, 
56 (2008) 2318.

[22] Arzt, E. Acta Materialia, 46 (1998) 5611.

[23] W.D. Nix, Metallurgical Transactions A. 20A (1989) 2217.

[24] G. Dehm, T.J. Balk, H. Edongue, E. Arzt, Microelectronic Engineering 70 (2003) 412.

[25] A. Misra, J.P. Hirth, R.G. Hoagland, Acta Mater. 53 (2005) 4817.

[26] D. Kiener, P.J. Guruprasad, S.M. Keralavarma, G. Dehm, A.A. Benzerga, Acta Mater. 59 (2011) 3825.

[27] S.H. Oh, M. Legros, D. Kiener, P. Gruber, G. Dehm, Acta Mater. 55 (2007) 5558.

[28] D. Kiener, W. Grosinger, G. Dehm, R. Pippan, Acta Mater. 56 (2008) 580.

[29] G. Dehm, Progress in Materials Science 54 (2009) 664.

[30] S.M. Han, T. Bozorg-Grayeli, J.R. Groves, W.D. Nix, Scr. Mater. 63 (2010) 1153.

[31] P.-O. Renault, E. Le Bourhis, P. Villain, Ph. Goudeau, K.F. Badawi, D. Faurie, Appl. Phys. Lett., 83 (2003) 473.

[32] D. Faurie, P.-O. Renault, E. Le Bourhis, P. Villain, Ph Goudeau, F. Badawi, Thin Solid Films 469-470 (2004) 201-205.

[33] I.C. Noyan, G. Sheikh, Mater. Res. Soc. Symp. Proc. 308 (1993) 3.

[34] J. Böhm, P. Gruber, R. Spolenak, A. Stierle, A. Wanner, and E. Arzt, Rev.Sci. Instrum. 75 (2004) 1110.

[35] J. Keckes, E. Eiper, K.J. Martinschitz, H. Köstenbauer, R. Daniel, C. Mitterer, Rev. Sci. Instrum. 78 (2007) 036103.

[36] D. Faurie, P. Djemia, E. Le Bourhis, P.-O. Renault, Y. Roussigné, S.M. Chérif, R. Brenner, O. Castelnau, G. Patriarche, P. Goudeau, Acta Mater. 58 (2010) 4998.

[37] G. Dehm, H.P. Wörgötter, S. Cazottes, J.M. Purswani, D. Gall, C. Mitterer, D. Kiener, Thin Solid Films 518 (2009) 1517.

[38] J.J. Vlassak and W.D. Nix, J. Mater. Res. 7 (1992) 3242.

[39] S. Eve, N. Hubert, O. Kraft, A. Last, D.Rabus, and M. Schlagenhof, Rev. Sci. Instrum. 
77 (2006) 103902.

[40] G. Geandier, D. Thiaudière, R. N. Randriamazaoro, R. Chiron, S. Djaziri, B. Lamongie, Y. Diot, E. Le Bourhis, P.O. Renault, P. Goudeau, A. Bouaffad, O. Castelnau, D. Faurie, F. Hild, Rev. Sci. Instrum. 81 (2010) 103903.

[41] K. Medjoubi, T. Bucaille, S. Hustache, J.-F. Bérar, N. Boudet, J.-C. Clemens, P. Delpierre, B. Dinkespiler, J. Synchrotron Rad. 17 (2010) 486-495.

[42] S. Djaziri, P.-O. Renault, F. Hild, E. Le Bourhis, Ph. Goudeau, D. Thiaudière, D. Faurie, J. Appl. Cryst. 44 (2011) 1071.

[43] U. Welzel, M. Leoni, E. J. Mittemeijer, Philos. Mag. 83 (2003) 603-630.

[44] U. Welzel, J. Ligot, P. Lamparter, A. C. Vermeulen, E. J. Mittemeijer, J. Appl. Cryst. $38(2005) 1$.

[45] N. Durand, K.F. Badawi, Ph. Goudeau, Thin Solid Films 275 (1996) 168-171.

[46] J. A. Thornton, D.W. Hoffman, Thin Solid Films 171 (1989) 5-31.

[47] L.B. Freund and S. Suresh, Thin film materials: Stress, defect formation and surface evolution, Cambridge University Press, 2003.

[48] D. Faurie, O. Castelnau, R. Brenner, P.O. Renault, E. Le Bourhis, Ph. Goudeau, J. Appl. Cryst. 42 (2009). 1073.

[49] Ludwik P., Elemente der Technologischen Mechanik, 1st edition, Springer, 1909..

[50] D. Faurie, P.-O. Renault, E. Le Bourhis, Ph. Goudeau, Acta Mater. 54 (2006) 45034513.

[51] G. Besnard, F. Hild, S. Roux, Exp. Mech. 46 (2006) 789.

[52] C. Le Bourlot, P. Landois, S. Djaziri, P.-O. Renault, E. Le Bourhis, P. Goudeau, M. Pinault, M. Mayne-L'Hermite, B. Bacroix, D. Faurie, O. Castelnau, P. Launois, S. Rouzière, J. Appl. Cryst. 45 (2012) 38.

[53] G. Geandier, P.-O. Renault, E. Le Bourhis, Ph. Goudeau, D. Faurie, C. Le Bourlot, Ph. Djémia, O. Castelnau, S. M. Chérif, Appl. Phys. Lett. 96 (2010) 041905. 
[54] Min Ha Lee, Jin Kyu Lee, Ki Buem Kim, Daniel J. Sordelet, Jürgen Eckert, Jung Chan Bae, Intermetallics, 18 (2010) 2009.

[55] S. Frank, P.A. Gruber, U.A. Handge, R. Spolenak, Acta Mater. 59 (2011) 5881. 


\section{Figure captions:}

Fig. 1: a) Raw image taken at $2 \theta=65.2^{\circ}, \Psi=80.0^{\circ}$ and $\Phi=0^{\circ}$. The image definition is $560 \times 720$ pixels. It represents a part of the tungsten diffraction pattern measured at 8.8 $\mathrm{keV}$ with the XPAD3.1 detector placed $536 \mathrm{~mm}$ away from the sample. b) Corrected image with shown integration sector (sector angle $=90^{\circ}$ and integration angle $=2^{\circ}$ ). c) $1 \mathrm{D}$ diffraction diagram obtained after radial integration after removing data between modules, which is not included in analyses.

Fig. 2: Superposition of X-ray elastic strains $\left(\varepsilon_{\mathrm{xx}}\right.$ and $\left.\varepsilon_{\mathrm{yy}}\right)$ and DIC strains $\left(\bar{\varepsilon}_{\mathrm{xx}}\right.$ and $\left.\bar{\varepsilon}_{\mathrm{yy}}\right)$ for different applied load states (equi-biaxial and non equi-biaxial loadings) for the [W$\mathrm{Cu}] \times 60$ multilayers. Open symbols represent experimental data from DIC measurements, and solid symbols correspond to experimental data from XRD measurements. The vertical bars represent the uncertainty of XRD and DIC strain measurements. Noteworthy the lines are only guide for eyes.

Fig. 3: $\ln (1 / \sin \theta)$ versus $\sin ^{2} \Psi$ plots for $\{211\}$-planes of $W$ sub-layers $(\alpha$-phase $)$ obtained for the $[\mathrm{W}-\mathrm{Cu}] \times 38$ multilayered thin film subjected to 27 consecutive equi-biaxial loadings (from T0 $=9 \mathrm{~N}$ to T26 $=160 \mathrm{~N}$ ) at azimuth angle $\Phi=0^{\circ}$. The inset shows the slope evolution of $\sin ^{2} \Psi$ plots during the tensile test. The dashed red line indicates the zero total stress (applied + residual), tensile fracture happening afterwards.

Fig. 4: X-ray applied strains as functions of the applied load for the (211) reflection of W$\alpha$-phase measured along twenty-six different $\Psi$-angles (values in legend at the right of the figure) at azimuth $\Phi=0^{\circ}$.

Fig. 5: X-ray applied elastic strains $\left(\varepsilon_{\mathrm{yy}}\right)$ and DIC macroscopic strains $\left(\bar{\varepsilon}_{\mathrm{yy}}\right)$ as functions of the applied load (equi-biaxial loadings) for the $[\mathrm{W}-\mathrm{Cu}] \times 38$ multilayers.

Fig. 6: X-ray applied elastic strains $\varepsilon_{\mathrm{yy}}$ as functions of DIC strains $\bar{\varepsilon}_{\mathrm{yy}}$ (equi-biaxial loadings) for the $[\mathrm{W}-\mathrm{Cu}] \times 38$ multilayers. The red dashed line indicates the obtained elastic limit (uncertainty is about the thickness of data points). 


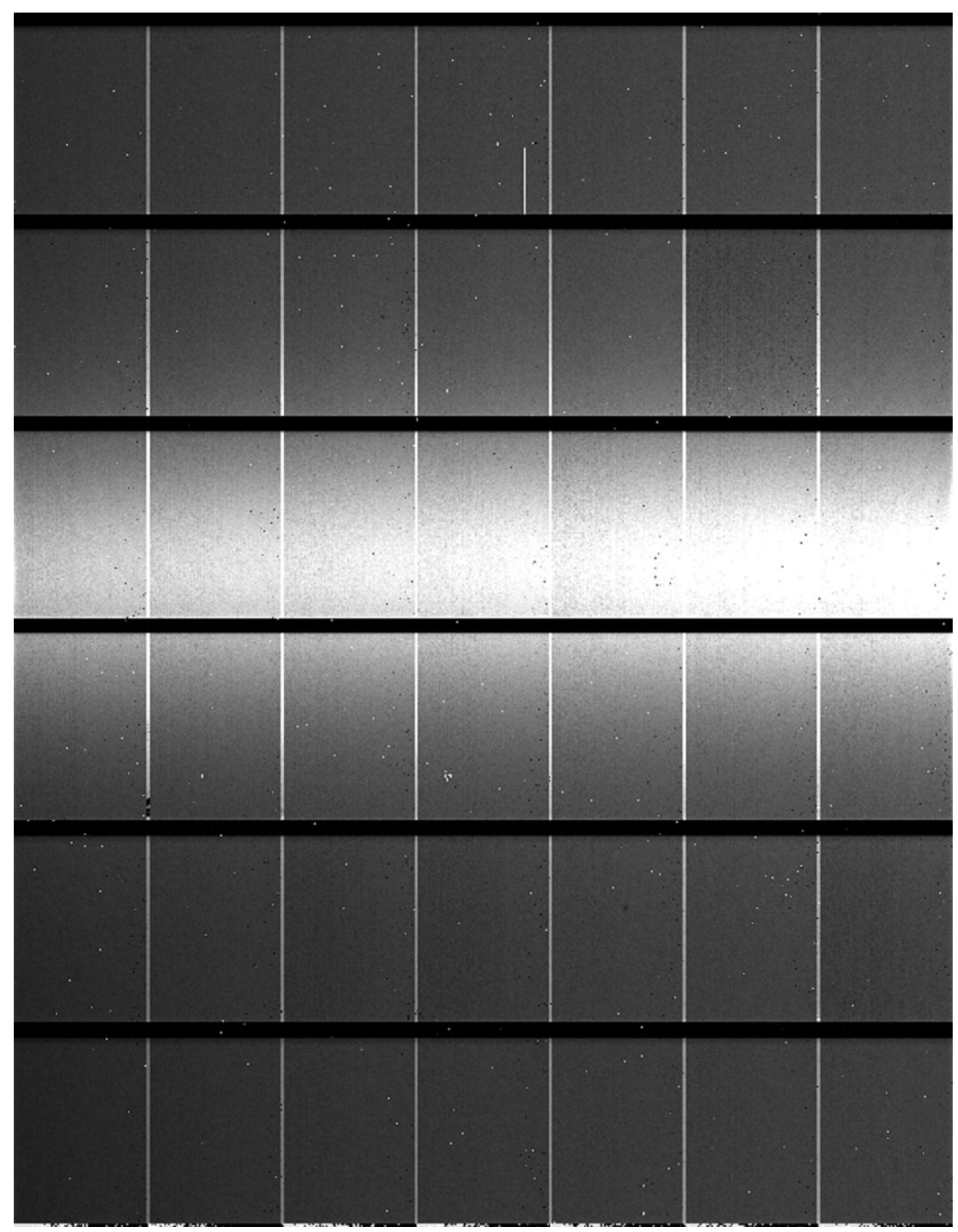

Figure 1a 


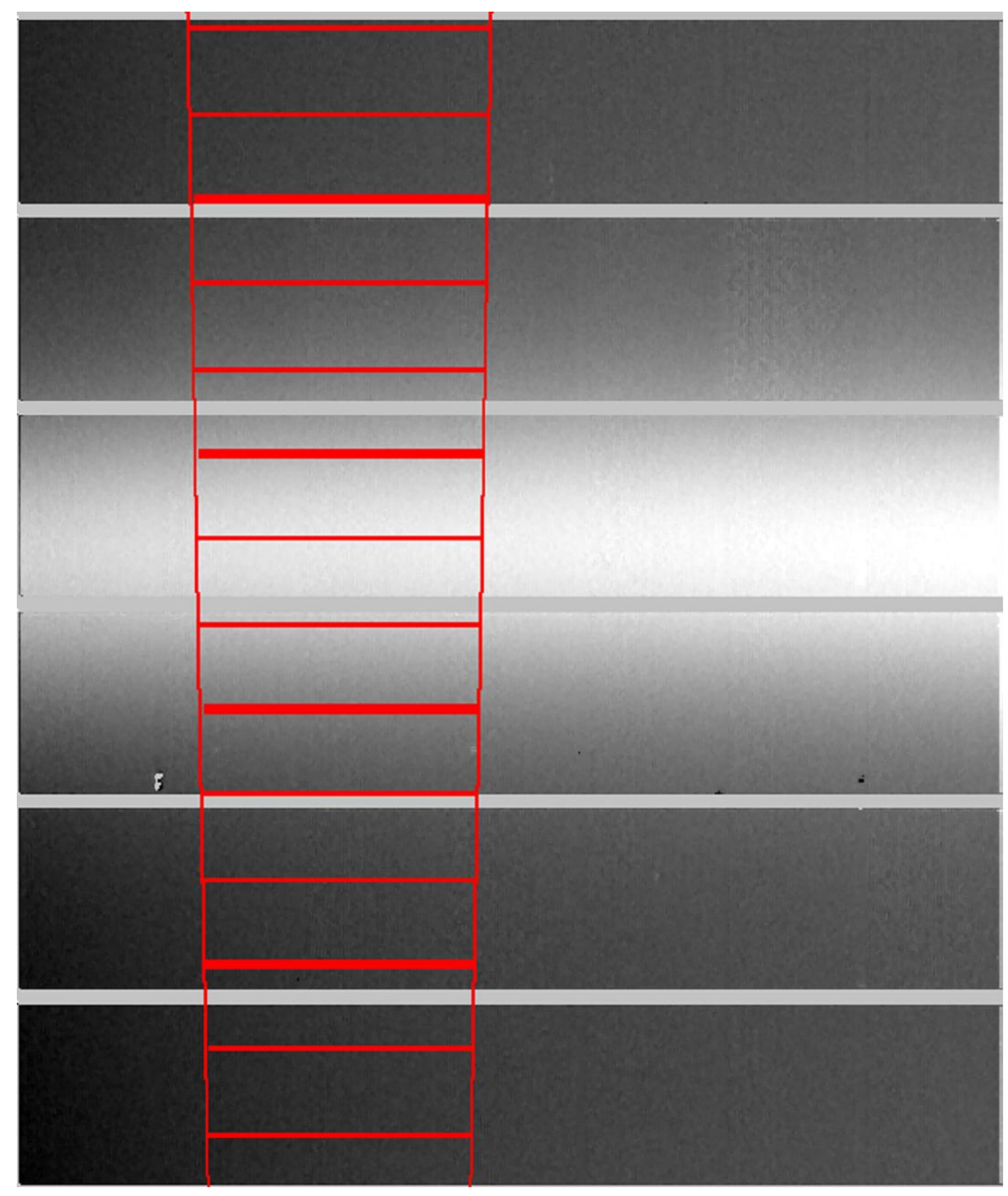

Figure 1b 


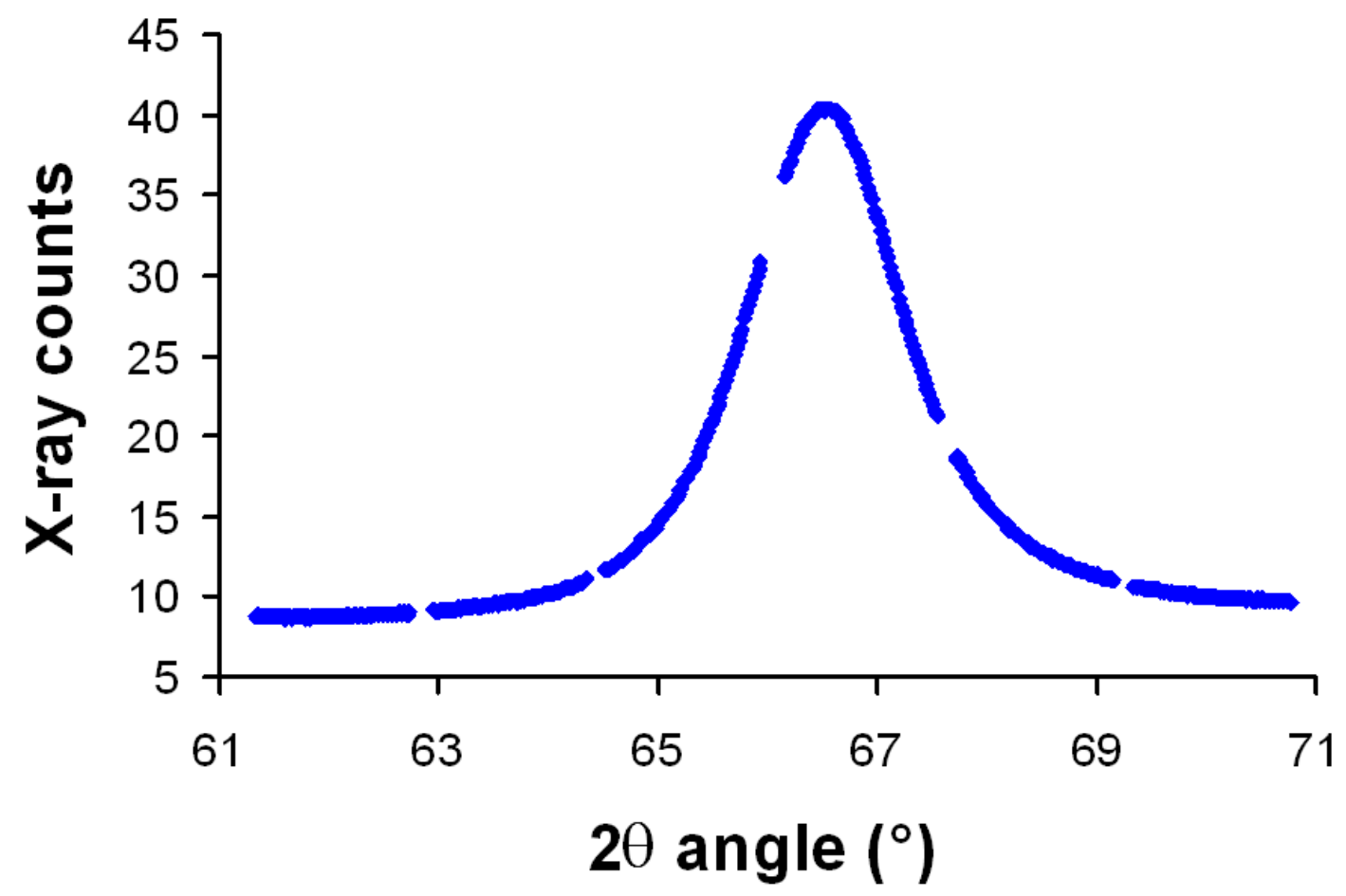

Figure 1c 


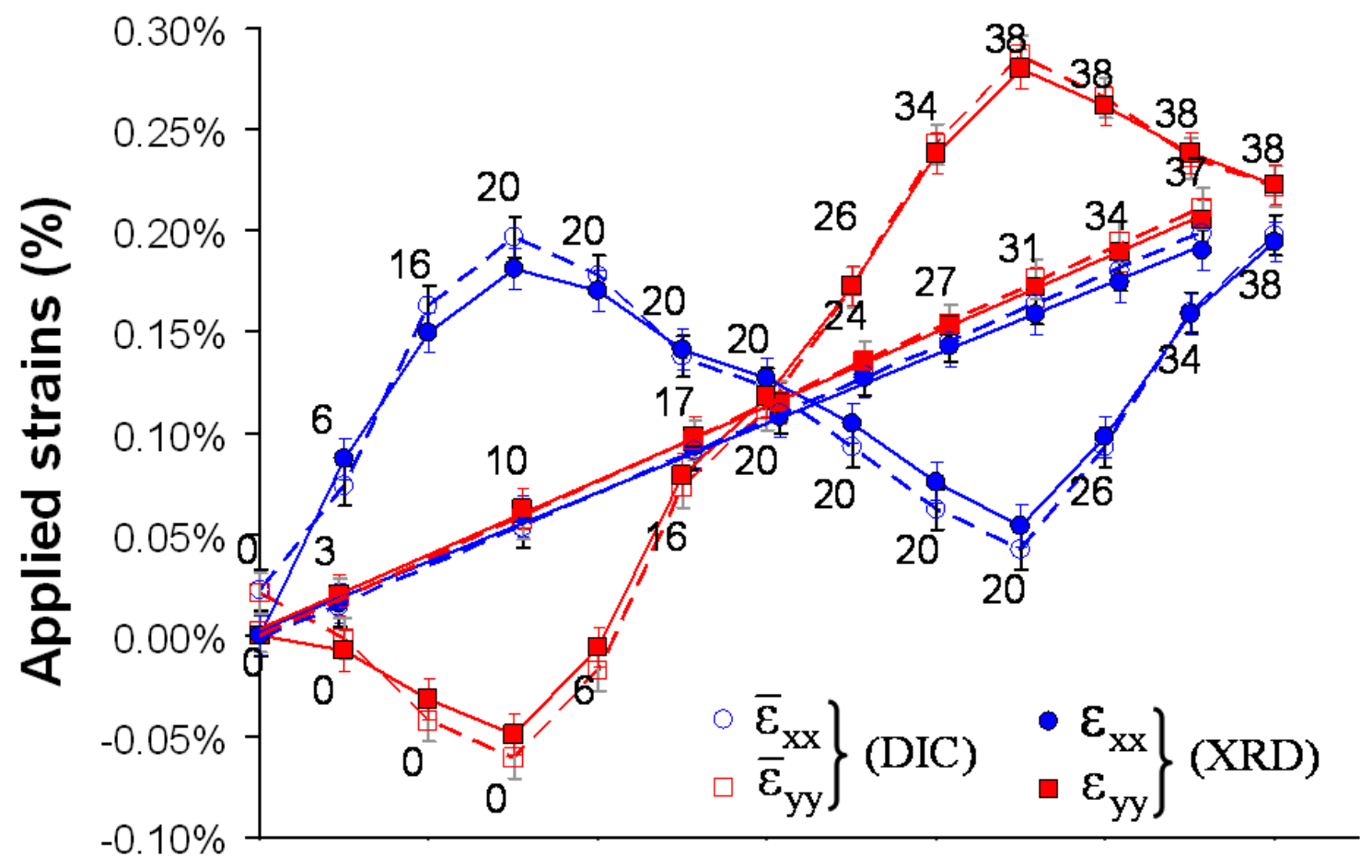

Figure 2 


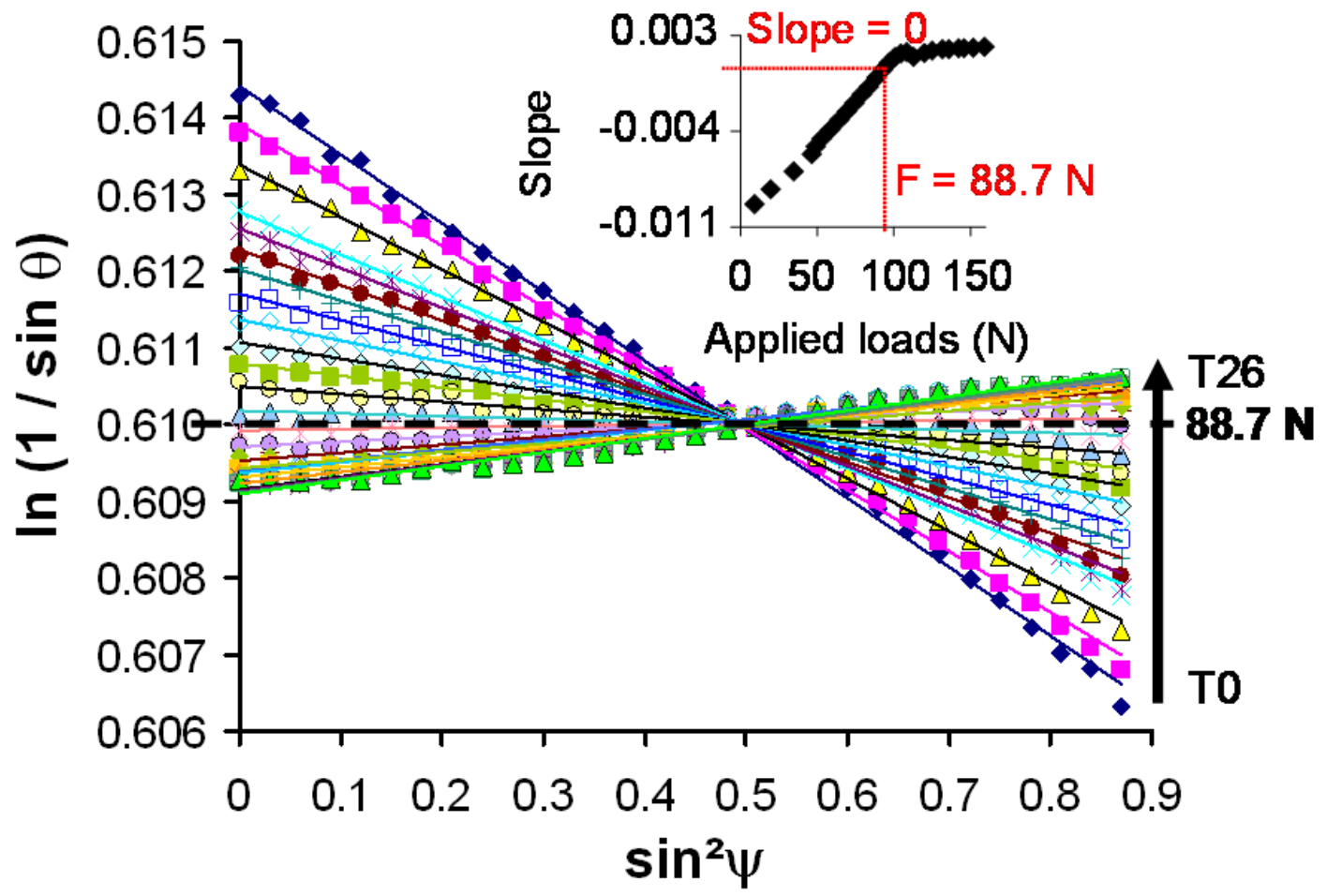

Figure 3 


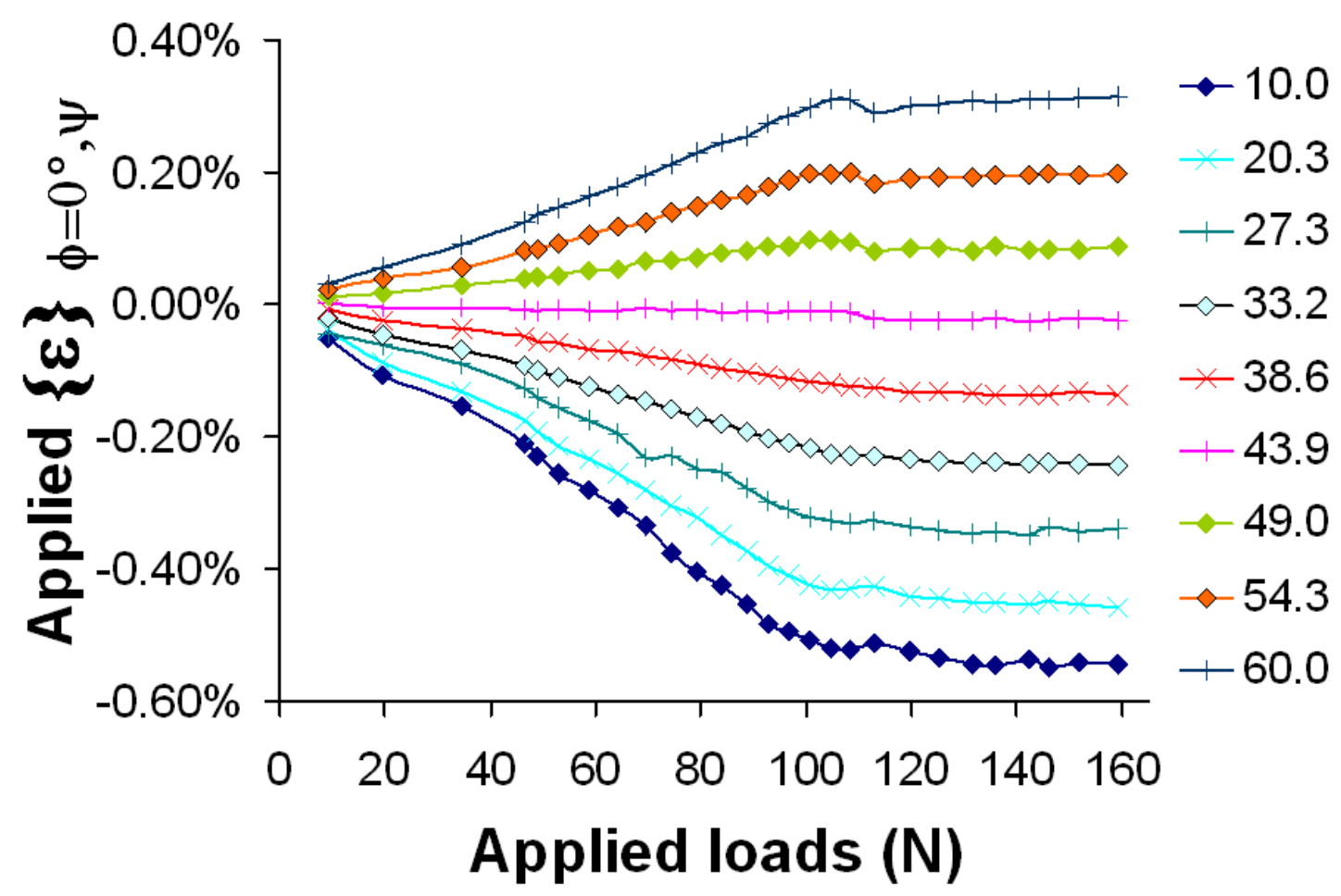

Figure 4 


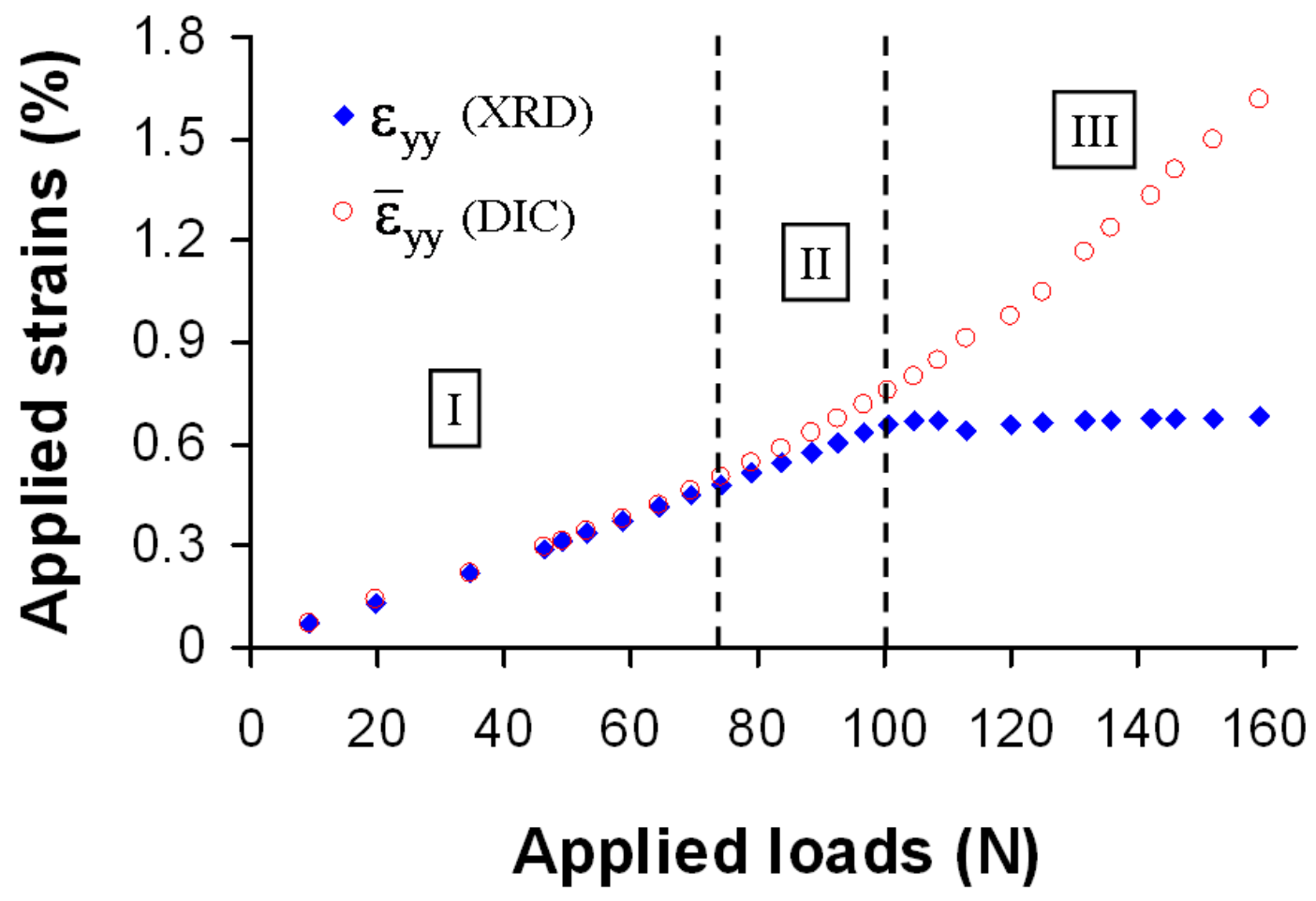

Figure 5 


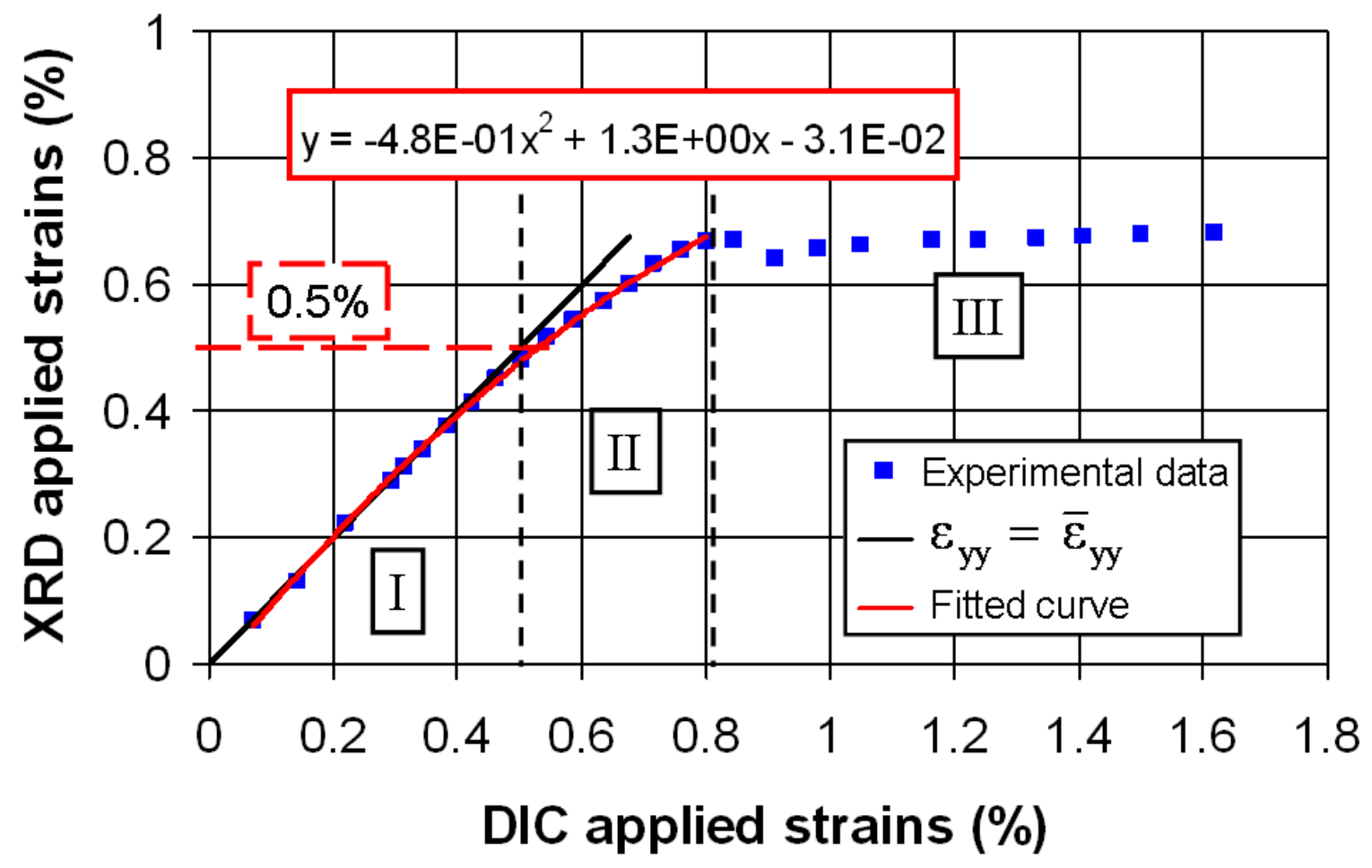

Figure 6 